\title{
A numerical study of the bearing capacity factor $\boldsymbol{N}_{\gamma}$
}

\author{
D.Y. Zhu, C.F. Lee, and H.D. Jiang
}

\begin{abstract}
Values of the bearing capacity factor $N_{y}$ are numerically computed using the method of triangular slices. Three assumptions of the value of $\psi$, the base angle of the active wedge, are analyzed, corresponding to the following three cases: (1) $\psi=\phi$, the internal friction angle; (2) $\psi=45^{\circ}+\phi / 2$; and (3) $\psi$ has a value such that $N_{\gamma}$ is a minimum. The location of the critical failure surface is presented and the numerical solutions to $N_{\gamma}$ for the three cases are approximated by simple equations. The influence of the base angle on the value of $N_{\gamma}$ is investigated. Comparisons of the present solutions are made with those commonly used in foundation engineering practice.
\end{abstract}

Key words: shallow foundation, bearing capacity, bearing capacity factor, limit equilibrium.

Résumé : Les valeurs du coefficient de capacité portante $N_{\gamma}$ sont calculées numériquement au moyen de la méthode des tranches triangulaires. Trois hypothèses de la valeur de $\psi$, l'angle de la base du coin actif, sont analysées, correspondant respectivement aux cas où $\psi$ est égal à l'angle de frottement interne $\phi, 45^{\circ}+\phi / 2$, et le cas de la valeur minimum de $N_{\gamma}$. On présente la localisation de la surface de rupture critique, et les solutions numériques de $N_{\gamma}$ sont calculées approximativement par des équations simples pour les trois cas. On étudie l'influence de l'angle de la base sur la valeur de $N_{\gamma}$. On compare les présentes solutions avec celles utilisées communément pour les fondations dans la pratique d'ingénieur.

Mots clés : fondation superficielle, capacité portante, coefficient de capacité portante, équilibre limite.

[Traduit par la Rédaction]

\section{Introduction}

For foundation design, the bearing capacity of a shallow strip footing is commonly determined by using the following Terzaghi equation:

$$
q_{\mathrm{u}}=q N_{q}+c N_{c}+\frac{1}{2} B \gamma N_{\gamma}
$$

where $q_{\mathrm{u}}$ is the ultimate bearing capacity; $c$ is the cohesion of the soil underneath the footing; $q$ is the surcharge above the base level of the footing; $\gamma$ is the unit weight of the soil; $B$ is the width of the footing; $N_{c}$ is the bearing capacity factor related to cohesion $c ; N_{q}$ is the bearing capacity factor related to surcharge $q$; and $N_{\gamma}$ is the bearing capacity factor related to $\gamma$ (Terzaghi 1943).

Analytical expressions derived from the theory of plasticity give $N_{c}$ and $N_{q}$ but not $N_{\gamma}$. Several methods have been employed to compute $N_{\gamma}$, including the limit equilibrium method (Terzaghi 1943; Meyerhof 1951), the method of characteristics (Sokolovski 1960), the limit analysis method

Received April 4, 2001. Accepted April 5, 2001. Published on the NRC Research Press Web site at http://cgj.nrc.ca on October 12, 2001 .

D.Y. Zhu and H.D. Jiang. College of Civil Engineering. Hohai University, Nanjing, 210098, China.

C.F. Lee.' Department of Civil Engineering, The University of Hong Kong, Pokfulam Road, Hong Kong.

'Corresponding author (e-mail: leecf@hkucc.hku.hk).
(Chen and Davidson 1973), and the finite element method (Griffiths 1982). The values of $N_{\gamma}$ given by these methods often vary considerably, and different formulae based on the limit equilibrium method are employed for computing $N_{\gamma}$ in the design codes of various countries (Sieffert and BayGress 2000). Discrepancies occur in the results mainly due to the different assumptions made regarding the geometry of the active wedge immediately under the footing and the different procedures used in the computation of passive earth pressure acting on the edge of the active wedge.

The geometry of the active wedge is defined by the base angle $\psi$ (Fig. 1), i.e., the inclination of the wedge with the horizontal, which has been assumed to be equal to $\phi$ (Terzaghi 1943), the friction angle; $45^{\circ}+\phi / 2$ (Meyerhof 1963; Vesic 1973 ); or a selected value such that $N_{\gamma}$ is a minimum (Hansen 1970; Vogel and Baracos 1973). The validity and merits of these assumptions have yet to be duly verified. In this paper, $N_{\gamma}$ values based on these three assumptions are computed and compared. In previous studies, the passive earth pressure on the edge of the active wedge was obtained using the limit equilibrium method with the assumption of a logarithmic spiral slip line bounding the general failure region. In this paper, the passive pressure is calculated using the method of triangular slices, which is within the framework of the limit equilibrium approach (Zhu and Qian 2000). With this method, the passive failure region is divided into a number of triangular slices and the critical base inclination of each slice is determined based on the principle of optimality. This results in minimal passive earth pressure without any restriction on the shape of the critical failure surface. The passive earth 
Fig. 1. General shear failure mechanism of soil under the footing.
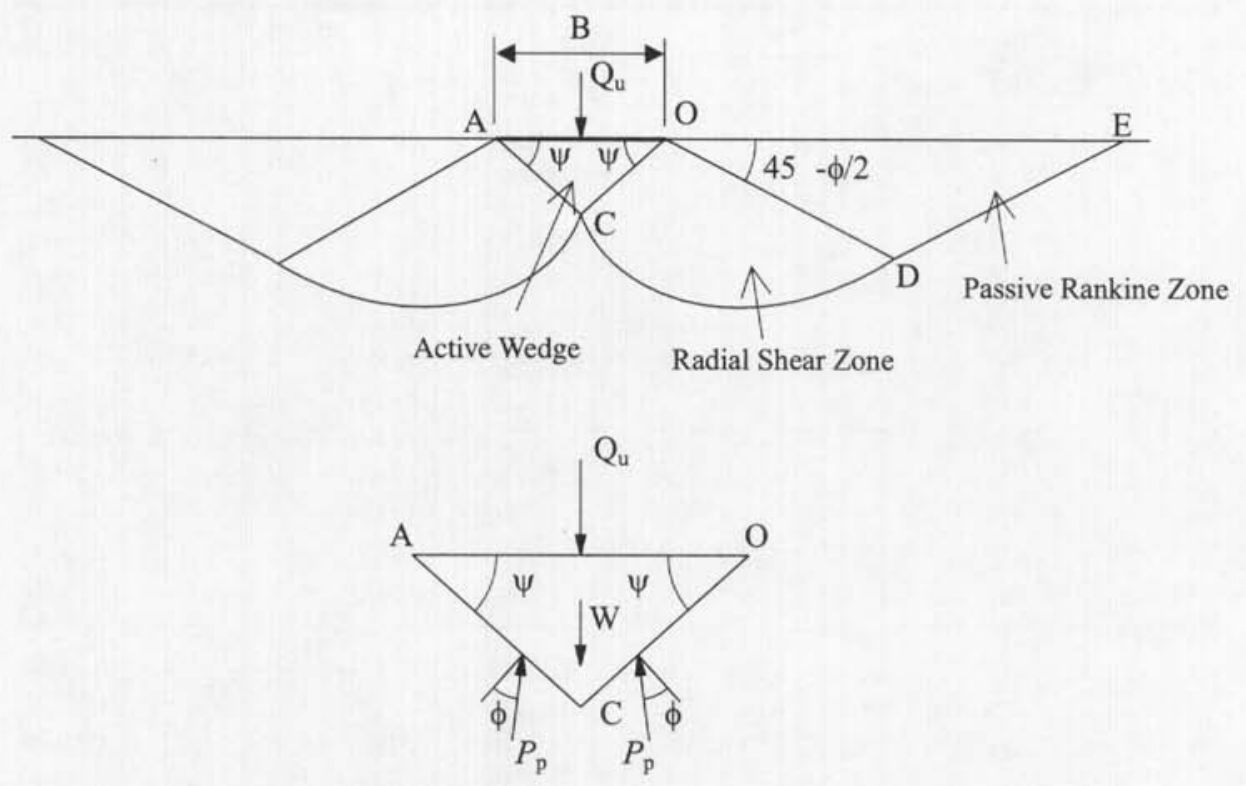

pressure coefficients thus calculated were found to be in good agreement with those from analytical solutions based on the theory of plasticity.

\section{Procedure}

A strip footing with a width $B$ subject to a vertical and central load $Q_{\mathrm{u}}$ on the surface of cohesionless soil is considered as shown in Fig. 1. It is assumed that under the ultimate load, a general symmetrical shear failure surface consisting of three zones is formed: active wedge (OAC in Fig. 1), radial shear zone (OCD), and passive Rankine zone (ODE). The active wedge is an isosceles triangle with a base angle of $\psi$. The weight $W$ of the active wedge is

$$
W=\frac{1}{2} \gamma \overline{O C}^{2} \sin 2 \psi
$$

The passive earth force $P_{\mathrm{p}}$ acting on the edge OC can be expressed as

$$
P_{p}=\frac{1}{2} \gamma k_{\mathrm{p}} \overline{O C}^{2}
$$

where $k_{\mathrm{p}}$ is the passive earth pressure coefficient, which can be directly determined using the method of triangular slices (Zhu and Qian 2000).

From vertical equilibrium of the active wedge, the ultimate load is given by

$$
\mathrm{Q}_{\mathrm{u}}=2 P_{\mathrm{p}} \cos (\psi-\phi)-W
$$

where $\phi$ is the internal friction angle.

Substituting eqs. [2] and [3] into eq. [4] and considering the relationship $\overline{O C}=B /(2 \cos \psi)$, we have

$$
Q_{u}=\frac{\gamma B^{2}}{8 \cos ^{2} \psi}\left[2 k_{\mathrm{p}} \cos (\psi-\phi)-\sin 2 \psi\right]
$$

From eq. [1], $Q_{\mathrm{u}}$ can also be expressed as
[6]

$$
Q_{u}=\frac{1}{2} \gamma N_{\gamma} B^{2}
$$

Comparing eqs. [5] and [6], we have

$$
N_{\gamma}=\frac{1}{4 \cos ^{2} \psi}\left[2 k_{\mathrm{p}} \cos (\psi-\phi)-\sin 2 \psi\right]
$$

Three assumptions of the value of $\psi$ are considered in this analysis corresponding to the following three cases: (1) $\psi=$ $\phi$, (2) $\psi=45^{\circ}+\phi / 2$, and (3) $\psi$ has a value that makes $N_{\gamma}$ a minimum. The values of $N_{\gamma}$ in these three cases are denoted $N_{\gamma}{ }^{(\mathrm{C} 1)}, N_{\gamma}{ }^{(\mathrm{C} 2)}$, and $N_{\gamma}{ }^{(\mathrm{C} 3)}$, respectively.

\section{Numerical values of $\boldsymbol{N}_{\gamma}$ and comparisons}

The numerical values of $N_{\gamma}$ for $\phi=1-50^{\circ}$ are presented in Table 1. The variation of $N_{y}$, with $\phi$ is shown in Fig. 2. The numerical values of $N_{\gamma}$ can be approximated by the following equations:

$$
\begin{aligned}
& N_{\gamma}=\left(2 N_{q}+1\right)(\tan \phi)^{1.35} \\
& N_{\gamma}=\left(2 N_{q}+1\right) \tan (1.07 \phi) \\
& N_{\gamma}=\left(2 N_{q}+1\right)(\tan \phi)^{1.45}
\end{aligned}
$$
for case 1 for case 2 for case 3

where

$$
N_{q}=\tan ^{2}\left(\frac{\pi}{4}+\frac{\phi}{2}\right) \cdot e^{\pi \tan \phi}
$$

Table 1 shows that the simple equations [8]-[10] agree well with the numerical results, with a maximum difference not exceeding $10 \%$, which can therefore be used in practice.

Comparisons of the present solution with those by other investigators are presented in Fig. 3. For case 1, Kumbhojkar (1993) has obtained numerical values of $N_{\gamma}$ using the logarithmic spiral method for calculating the passive earth pressure acting on the edge between the active wedge and the radial shear zone. Kumbhojkar's solutions are plotted in Fig. 3, 
Table 1. Numerical values of $N_{\gamma}$

\begin{tabular}{|c|c|c|c|c|c|c|c|}
\hline \multirow[b]{2}{*}{$\phi\left({ }^{\circ}\right)$} & \multicolumn{3}{|c|}{ Numerical $N_{y}$} & \multirow[b]{2}{*}{$N_{q}$} & \multicolumn{3}{|c|}{ Approximate $N_{\gamma} /$ numerical $N_{\gamma}$} \\
\hline & Case 1 & Case 2 & Case 3 & & Case 1 & Case 2 & Case 3 \\
\hline 1 & 0.012 & 0.058 & 0.011 & 1.094 & 1.094 & 1.027 & 0.812 \\
\hline 2 & 0.031 & 0.124 & 0.025 & 1.197 & 1.182 & 1.021 & 1.028 \\
\hline 3 & 0.058 & 0.200 & 0.045 & 1.309 & 1.169 & 1.015 & 1.121 \\
\hline 4 & 0.094 & 0.286 & 0.071 & 1.432 & 1.131 & 1.011 & 1.146 \\
\hline 5 & 0.139 & 0.385 & 0.107 & 1.568 & 1.108 & 1.007 & 1.131 \\
\hline 6 & 0.195 & 0.497 & 0.152 & 1.726 & 1.087 & 1.004 & 1.111 \\
\hline 7 & 0.262 & 0.624 & 0.208 & 1.879 & 1.069 & 1.002 & 1.095 \\
\hline 8 & 0.343 & 0.769 & 0.275 & 2.058 & 1.056 & 1.001 & 1.081 \\
\hline 9 & 0.440 & 0.935 & 0.356 & 2.255 & 1.041 & 1.000 & 1.068 \\
\hline 10 & 0.552 & 1.123 & 0.453 & 2.471 & 1.034 & 1.000 & 1.059 \\
\hline 11 & 0.684 & 1.337 & 0.568 & 2.710 & 1.028 & 1.000 & 1.051 \\
\hline 12 & 0.842 & 1.582 & 0.707 & 2.973 & 1.020 & 1.001 & 1.041 \\
\hline 13 & 1.023 & 1.860 & 0.875 & 3.264 & 1.017 & 1.003 & 1.027 \\
\hline 14 & 1.238 & 2.178 & 1.069 & 3.586 & 1.012 & 1.004 & 1.020 \\
\hline 15 & 1.488 & 2.540 & 1.309 & 3.941 & 1.009 & 1.006 & 1.006 \\
\hline 16 & 1.775 & 2.955 & 1.584 & 4.335 & 1.009 & 1.008 & 0.998 \\
\hline 17 & 2.114 & 3.429 & 1.921 & 4.772 & 1.007 & 1.010 & 0.984 \\
\hline 18 & 2.509 & 3.973 & 2.323 & 5.258 & 1.006 & 1.013 & 0.971 \\
\hline 19 & 2.964 & 4.597 & 2.793 & 5.798 & 1.008 & 1.015 & 0.961 \\
\hline 20 & 3.499 & 5.313 & 3.367 & 6.399 & 1.008 & 1.018 & 0.947 \\
\hline 21 & 4.123 & 6.138 & 4.033 & 7.071 & 1.008 & 1.020 & 0.937 \\
\hline 22 & 4.852 & 7.089 & 4.796 & 7.821 & 1.009 & 1.023 & 0.932 \\
\hline 23 & 5.701 & 8.187 & 5.673 & 8.661 & 1.011 & 1.025 & 0.932 \\
\hline 24 & 6.698 & 9.457 & 6.685 & 9.603 & 1.012 & 1.027 & 0.935 \\
\hline 25 & 7.867 & 10.930 & 7.864 & 10.662 & 1.013 & 1.029 & 0.939 \\
\hline 26 & 9.240 & 12.643 & 9.240 & 11.854 & 1.014 & 1.031 & 0.944 \\
\hline 27 & 10.856 & 14.638 & 10.849 & 13.199 & 1.016 & 1.033 & 0.950 \\
\hline 28 & 12.761 & 16.968 & 12.740 & 14.720 & 1.017 & 1.034 & 0.956 \\
\hline 29 & 15.013 & 19.697 & 14.959 & 16.443 & 1.018 & 1.035 & 0.963 \\
\hline 30 & 17.682 & 22.901 & 17.579 & 18.401 & 1.018 & 1.035 & 0.970 \\
\hline 31 & 20.851 & 26.676 & 20.672 & 20.631 & 1.019 & 1.036 & 0.977 \\
\hline 32 & 24.625 & 31.138 & 24.346 & 23.177 & 1.019 & 1.035 & 0.984 \\
\hline 33 & 29.136 & 36.429 & 28.719 & 26.092 & 1.019 & 1.034 & 0.990 \\
\hline 34 & 34.542 & 42.726 & 33.941 & 29.440 & 1.019 & 1.032 & 0.997 \\
\hline 35 & 41.048 & 50.247 & 40.200 & 33.296 & 1.018 & 1.030 & 1.003 \\
\hline 36 & 48.902 & 59.269 & 47.735 & 37.752 & 1.016 & 1.027 & 1.008 \\
\hline 37 & 58.426 & 70.137 & 56.855 & 42.920 & 1.014 & 1.024 & 1.013 \\
\hline 38 & 70.025 & 83.287 & 67.899 & 48.933 & 1.012 & 1.020 & 1.018 \\
\hline 39 & 84.210 & 99.274 & 81.366 & 55.957 & 1.009 & 1.014 & 1.022 \\
\hline 40 & 101.653 & 118.786 & 97.926 & 64.195 & 1.004 & 1.009 & 1.025 \\
\hline 41 & 123.203 & 142.746 & 118.246 & 73.896 & 1.000 & 1.002 & 1.027 \\
\hline 42 & 149.981 & 172.339 & 143.431 & 85.373 & 0.994 & 0.994 & 1.028 \\
\hline 43 & 183.451 & 209.096 & 174.829 & 99.013 & 0.987 & 0.986 & 1.029 \\
\hline 44 & 225.420 & 255.049 & 214.058 & 115.307 & 0.980 & 0.977 & 1.029 \\
\hline 45 & 278.540 & 312.880 & 263.746 & 134.872 & 0.972 & 0.966 & 1.027 \\
\hline 46 & 346.205 & 386.183 & 326.590 & 158.500 & 0.963 & 0.955 & 1.024 \\
\hline 47 & 433.047 & 479.815 & 407.403 & 187.204 & 0.953 & 0.942 & 1.020 \\
\hline 48 & 545.391 & 600.384 & 511.186 & 222.297 & 0.941 & 0.928 & 1.015 \\
\hline 49 & 691.958 & 757.000 & 646.853 & 265.494 & 0.929 & 0.914 & 1.008 \\
\hline 50 & 884.930 & 962.325 & 824.313 & 319.053 & 0.915 & 0.898 & 1.000 \\
\hline
\end{tabular}

which shows that his numerical values are, to a certain degree, higher than those from the present solution, especially when the internal friction angle of the soil is large. This discrepancy possibly results from the different approaches used in searching the critical slip surface. Terzaghi (1943) pub- lished well-known curves of bearing capacity factors versus $\phi$. It is difficult to precisely reproduce his solution. Hence, only three numerical values are plotted in Fig. 3 for comparison. It is shown that Terzaghi's solution is in agreement with that of Kumbhojkar when $\phi$ is less than $45^{\circ}$. 
Fig. 2. Variation of $N_{\gamma}$ with $\phi$.

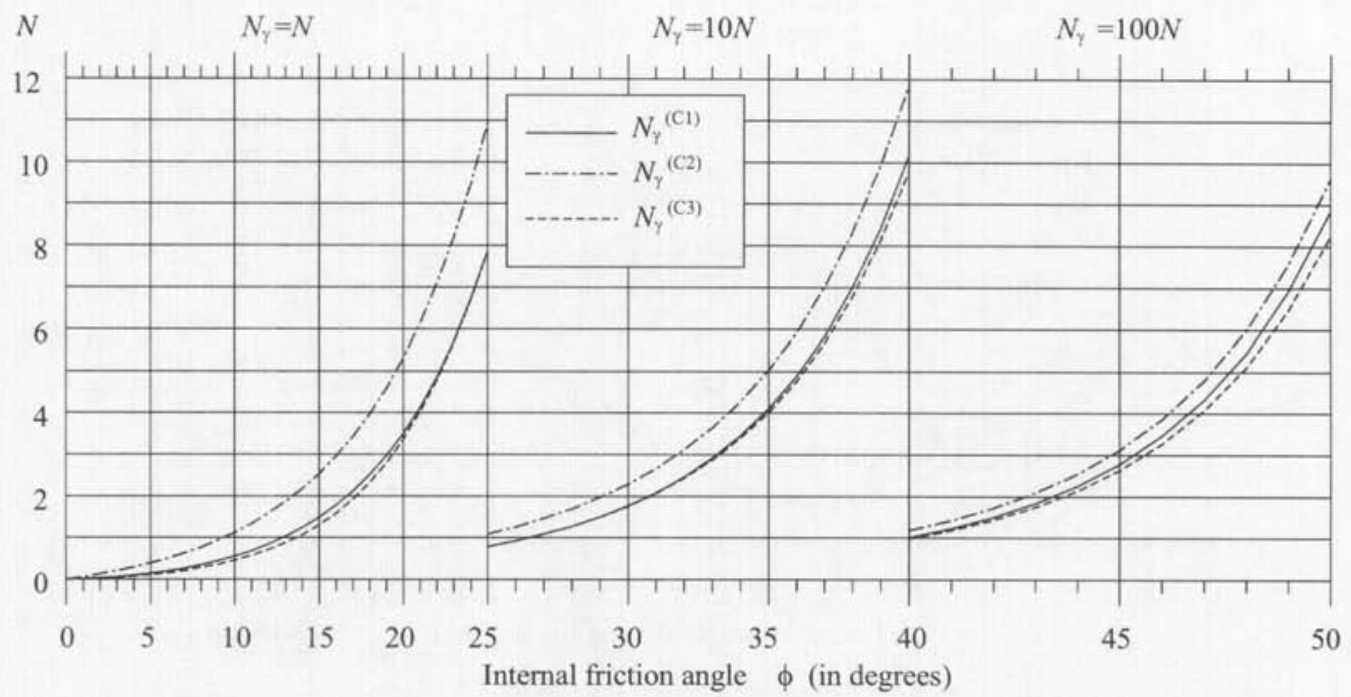

For case 2, two widely used formulae were provided by Meyerhof (1963)

[11] $\quad N_{\gamma}=\left(N_{q}-1\right) \tan (1.4 \phi)$

and Vesic (1973)

$$
N_{\gamma}=2\left(N_{q}+1\right) \tan \phi
$$

Figure 3 shows that the present solution is in good agreement with that of Vesic (1973) when $\phi$ is less than $35^{\circ}$, whereas the solution of Meyerhof (1963) generally gives lower values of $N_{\gamma}$ in comparison to the other two solutions.

For case 3, Hansen (1970) gave the following formula for computing $N_{\gamma}$ :

$$
N_{\gamma}=1.5\left(N_{q}-1\right) \tan \phi
$$

Vogel and Baracos (1973) also gave numerical results for several values of $\phi$, which are plotted in Fig. 3 along with those based on eq. [13]. The present solution agrees well with that of Vogel and Baracos. The results provided by eq. [13], based on the solution of Hansen (1970), are lower in value.

Figure 2 shows that the difference in corresponding values of $N_{y}$ between case 1 and case 3 is relatively small. Moreover, the influence of the base angle $\psi$ on the value of $N_{\gamma}$ computed is not large, as illustrated in Fig. 4. For example, for $\phi=40^{\circ}$, when $\psi$ increases from $34^{\circ}$ to $61^{\circ}, N_{\gamma}$ will only decrease by less than $10 \%$.

It must be pointed out that the present solutions for the bearing capacity factor $N_{\gamma}$ are in the context of limit equilibrium. Strictly speaking, they are neither lower nor upper bounds to the exact solutions. Since the passive earth pressure coefficient required for calculating $N_{y}$ is obtained to a high degree of accuracy by the method of triangular slices, the calculated values of $N_{y}$ can be regarded as nearly accurate for the adopted assumption regarding the base angle of the active wedge. Recently, several investigators have developed the least upper-bound solutions to $N_{\gamma}$ by means of limit analysis using an optimization technique (Michalowski 1997; Soubra 1999; Zhu 1999). Their results are nearly identical for both the symmetrical and the one-sided failure mecha- nisms. Comparison between the values of $N_{\gamma}$ obtained with the present method and those from the least upper-bound solutions are tabulated in Table 2. It can be seen in Table 2 that the least upper-bound solutions to $N_{y}$ are in close agreement with those from the present method for case 2 . The values of $N_{\gamma}$ in case 3 are the lowest of all three cases and may therefore approximate the lower-bound solutions, since they are minimized with respect to the base angle, and the associated passive earth pressure coefficient is nearly exactly obtained by using the method of triangular slices.

\section{Location of critical failure surfaces}

The location of the critical failure surface in soil under ultimate loading is of interest in design. Figure 5 shows that the extent of the failure region in case 2 is larger than those for cases 1 and 3 . It is interesting to note that for case 3 , when $\phi$ is equal to or less than $20^{\circ}$, the critical value of $\psi$ is zero. This was first found by Vogel and Baracos (1973). Comparison of the locations of the critical failure surface is shown in Fig. 6. The location of the critical failure surface given by Kumbhojkar (1993) deviates substantially from the present solution, and this results in a large discrepancy in the values of $N_{y}$ calculated. Kumbhojkar restricted the center of the logarithmic spiral to the line that makes an angle of $45^{\circ}-$ $\phi / 2$ with the horizontal. Vogel and Baracos (1973) imposed no such restriction on the position of the center of the logarithmic spiral and gave locations of the critical failure surface which are in good agreement with those obtained with the present method of triangular slices.

\section{Conclusions}

The method of triangular slices is an effective method for computing the values of the bearing capacity factor $N_{\gamma}$. Three cases of base angle assumption are taken into account in the present analysis. The values of $N_{y}$ computed based on the assumption of $45^{\circ}+\phi / 2$ are in close agreement with the least upper-bound solutions by limit analysis, whereas those values which are minimized with respect to the base angle ap- 
Fig. 3. Comparison of $N_{\gamma}$ values computed in the present study with those from other investigators.
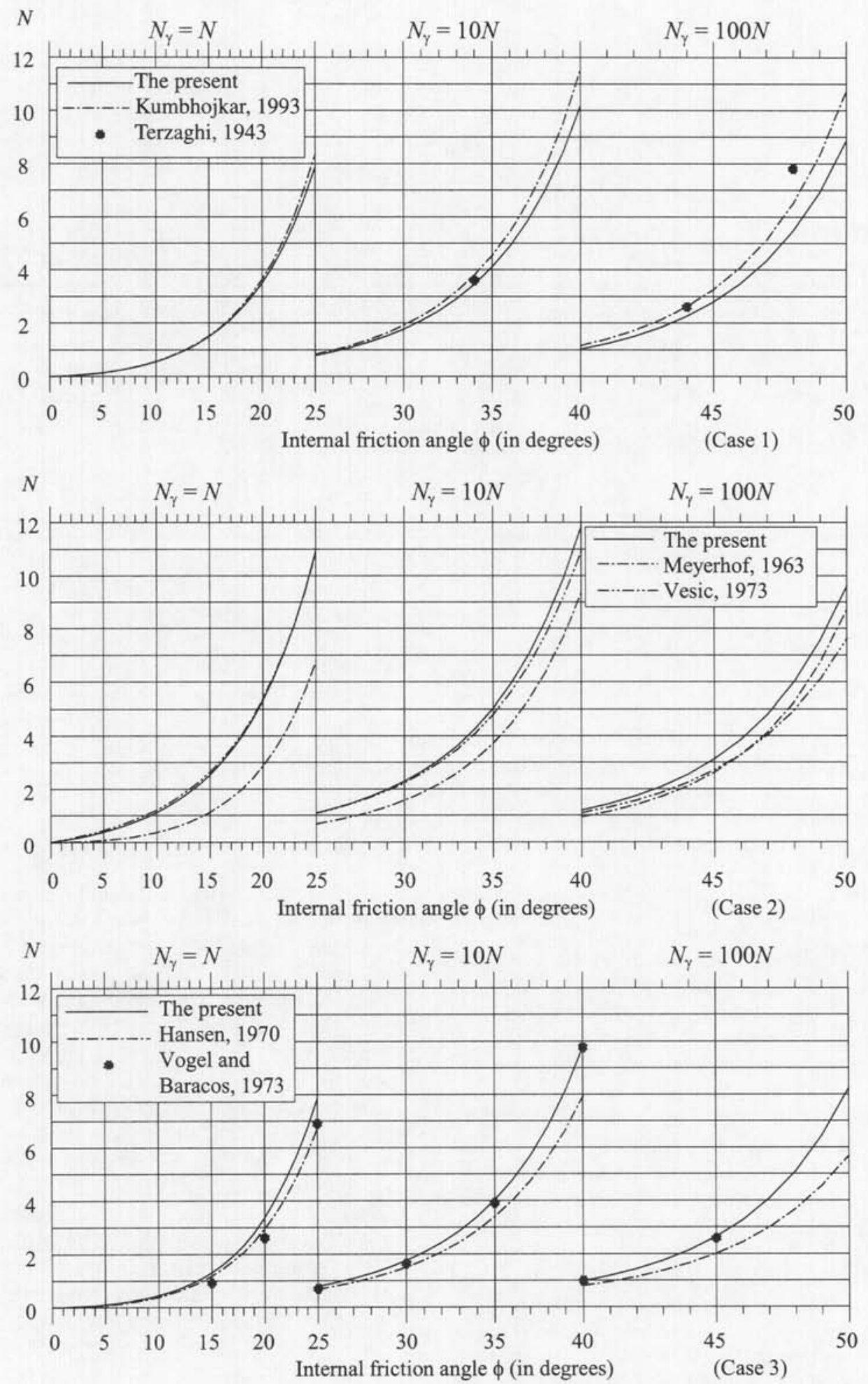

proximately represent the lower bound. The values of $N_{\gamma}$ computed based on the Terzaghi assumption of $\psi=\phi$ are slightly larger than the minimum. Simple equations for $N_{\gamma}$ are suggested that can be used to approximate the numerical values quite accurately, allowing them to be applied in the design of shallow foundations.

\section{Acknowledgement}

The study was financially supported by the Jockey Club Research and Information Center for Landslip Prevention and Land Development, at the University of Hong Kong. This support is gratefully acknowledged. 
Fig. 4. Effect of $\psi$ on $N_{\gamma}$

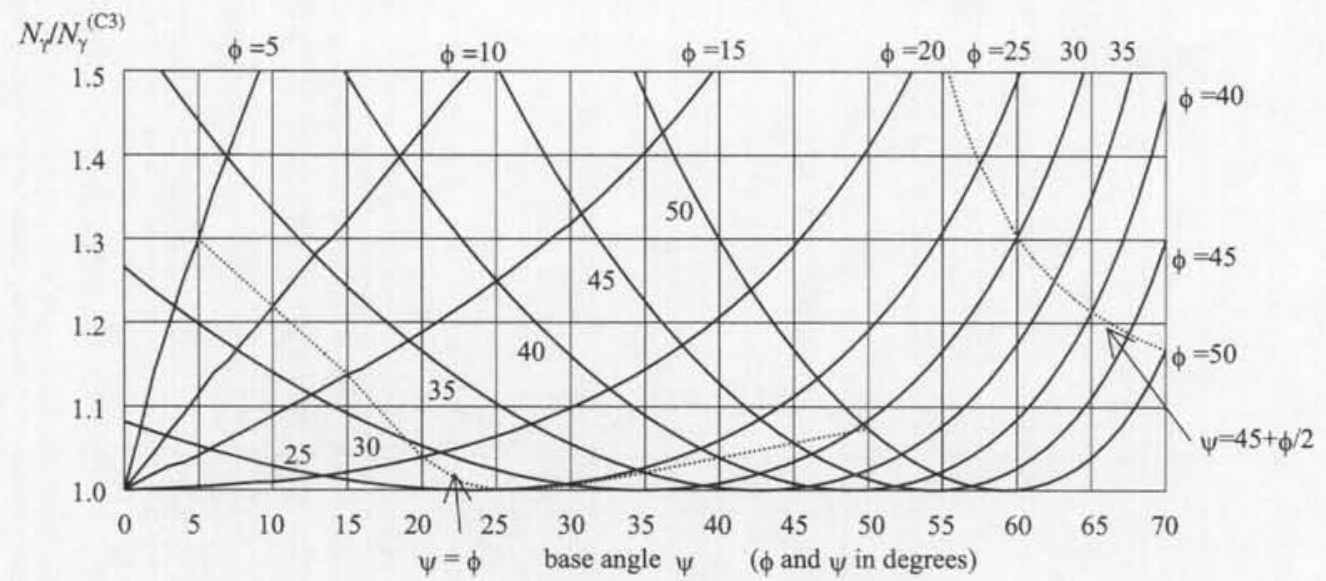

Fig. 5. Critical failure surfaces under ultimate loading.
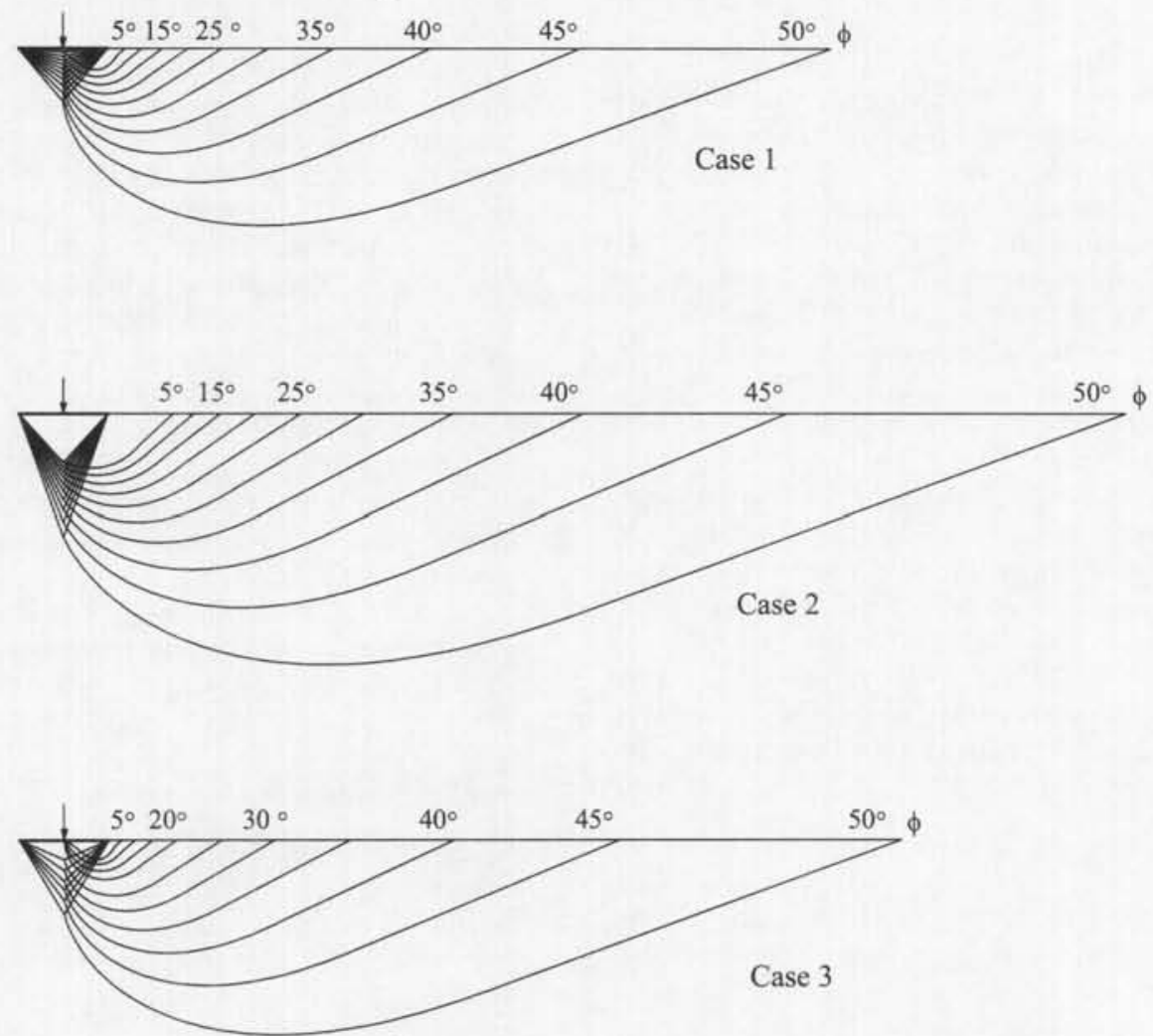

Table 2. Comparison of $N_{y}$ values from the present method with those from limit analysis.

\begin{tabular}{|c|c|c|c|c|c|}
\hline \multirow[b]{3}{*}{$\phi\left({ }^{\circ}\right)$} & \multirow{2}{*}{\multicolumn{3}{|c|}{ Present solutions }} & \multicolumn{2}{|c|}{ Least upper-bound solutions } \\
\hline & & & & \multirow{2}{*}{$\begin{array}{l}\text { Symmetrical } \\
\text { mechanism }\end{array}$} & \multirow{2}{*}{$\begin{array}{l}\text { One-sided } \\
\text { mechanism }\end{array}$} \\
\hline & Case 1 & Case 2 & Case 3 & & \\
\hline 5 & 0.139 & 0.385 & 0.107 & 0.181 & 0.247 \\
\hline 10 & 0.552 & 1.123 & 0.453 & 0.706 & 0.845 \\
\hline 15 & 1.488 & 2.540 & 1.309 & 1.937 & 2.095 \\
\hline 20 & 3.499 & 5.313 & 3.367 & 4.466 & 4.659 \\
\hline 25 & 7.867 & 10.930 & 7.864 & 9.760 & 10.031 \\
\hline 30 & 17.682 & 22.901 & 17.579 & 21.384 & 21.805 \\
\hline 35 & 41.048 & 50.247 & 40.200 & 48.654 & 49.381 \\
\hline 40 & 101.653 & 118.786 & 97.926 & 118.750 & 120.150 \\
\hline 45 & 278.540 & 312.880 & 263.746 & 322.622 & 325.766 \\
\hline 50 & 884.930 & 962.325 & 824.313 & 1025.064 & 1033.480 \\
\hline
\end{tabular}


Fig. 6. Comparison of location of critical failure surfaces.
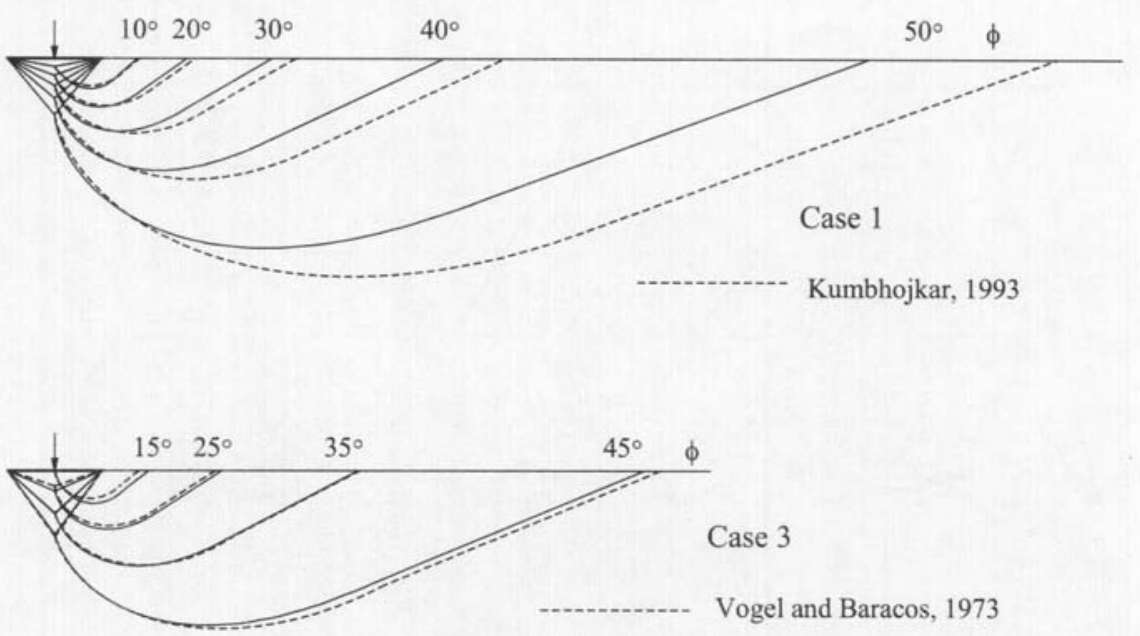

\section{References}

Chen, W.F., and Davidson, H.L. 1973. Bearing capacity determination by limit analysis. Journal of the Soil Mechanics and Foundations Division, ASCE, 99(6): 433-449.

Griffiths, D.V. 1982. Computation of bearing capacity factors using finite elements. Géotechnique, 32(3): 195-202.

Hansen, J.B. 1970. A revised and extended formula for bearing capacity. Danish Geotechnical Institute, Bulletin 28, pp. 5-11

Kumbhojkar, A.S. 1993. Numerical evaluation of Terzaghi's $N_{\%}$ Journal of Geotechnical Engineering, ASCE, 119(3): 598-607.

Meyerhof, G.G. 1951. The ultimate bearing capacity of foundations. Géotechnique, 1(2): 301-332.

Meyerhof, G.G. 1963. Some recent research on the bearing capacity of foundations. Canadian Geotechnical Journal, 1: 16-31.

Michalowski, R.L. 1997. An estimate of the influence of soil weight on bearing capacity using limit analysis. Soils and Foundations, Japanese Geotechnical Society, 40(1): 123-129.

Sieffert. J.G., and Bay-Gress, Ch. 2000. Comparison of European bearing capacity calculation methods for shallow foundations. Geotechnical Engineering, Proceedings of the Institution of Civil Engineers, 143: 65-74.
Sokolovski, V.V. 1960. Statics of soil media. Butterworth Scientific Publications, London, U.K.

Soubra, A.-H. 1999. Upper-bound solution for bearing capacity of foundations. Journal of Geotechnical and Geoenvironmental Engineering, ASCE, 125(1): 59-68

Terzaghi, K. 1943. Theoretical soil mechanics. 5th ed. John Wiley and Sons Inc., New York.

Vesic, A.S. 1973. Analysis of ultimate loads of shallow foundations. Journal of the Soil Mechanics and Foundations Division, ASCE, 99(1): 45-73.

Vogel, C., and Baracos, A. 1973. Analysis of ultimate loads of shallow foundations: Discussion. Journal of the Soil Mechanics and Foundations Division, ASCE, 99(11): 1016-1018.

Zhu, D.Y. 1999. The least upper-bound solutions for bearing capacity factor $N_{r}$. Soils and Foundations, Japanese Geotechnical Society, 40(1): 123-129.

Zhu, D.-Y., and Qian, Q. 2000. Determination of passive earth pressure coefficients by the method of triangular slices. Canadian Geotechnical Journal, 37: 485-491. 